No. 39 of the Committee for State Control over Emergency Situations and Industrial Safety of the Republic of Kazakhstan dated September 22, 2008.

https://doi.org/10.31713/m1015

\title{
THEORY AND PRACTICE OF DETERMINING THE CATEGORY HAZARD OF COAL MINES BY THE GAS FACTOR
}

E. Filatieva
Volodymyr Dahl East Ukrainian National University, Senior
Lecturer, Ukraine

A. Oleinichenko

Volodymyr Dahl East Ukrainian National University, Senior Lecturer, Ukraine

M. Filatiev
$\begin{aligned} & \text { Volodymyr Dahl East Ukrainian National University, Doctor } \\ & \text { of Engineering Sciences, Associate Professor, Ukraine } \\ & \text { V. Sokolenko }\end{aligned}$
Volodymyr Dahl East Ukrainian National University, Candidate of
technical science, Associate Professor, Ukraine

\section{Annotation}

A comparative analysis of the theoretical and practical definition of the category hazard of coal mines by gas factor based on experimental data obtained in real conditions of mining gas-bearing coal seams is presented. The mine's hazard category by gas factor is determined in accordance with the current regulatory document. The processing of experimental data obtained in field studies leads to contradictions in the requirements for the safe mining of gas-bearing coal seams. The necessity of changing the regulatory framework for predicting methane release and establishing the category hazard of mines by gas factor is substantiated, as well as the theoretical part of the research is experimentally confirmed and practical proposals are given to improve the requirements of regulatory documents for the safe mining of gas-bearing coal seams.

The gas release from seven possible sources, the exposed surface of the working face, the undermined adjacent seams and their enclosing rocks, the overworked adjacent seams and enclosing rocks, the worked-out space of the stopped lavas, are accepted for consideration. The studies have shown that by removal the bottom from cut and the area of the mined-out space of the operated section and the wing of the 
mine field, taking into account the stopped longwalls, it is possible to predict the processes of rock displacement that determine the absolute gas release from the undermined sources.

\section{Introduction}

Establishment of the category of mines for the hazard of methane emission is carried out in accordance with the normative document [1] using the relative gas emission per one ton of mined coal. This technique was developed for the conditions of Donbass in the fifties of the last century. At that time, mines were mined at shallow and medium depths. The main source of gas release into the mine workings of extraction areas (more than 60\%) was the developed seam. The gas balance in most cases was characterized by methane release from the broken coal and the exposed surface of the working face. The direct relationship of gas emission from these sources with the level of coal production suggested their direct proportional relationship. This was a theoretical justification for dividing mines according to their category using the amount of methane per ton of coal mined.

A little later, it was found that the relative gas release is not a constant parameter, but depends on the level of coal production [2]. This circumstance was not taken into account when developing a forecast of gas emission in the relevant regulatory documents, including in the current manual [3]. As a result of this, significant discrepancies were subsequently revealed between the experimental data on gas evolution and their predicted values [4]. In addition, if we proceed from the fact of a decrease in the relative gas abundance with an increase in coal production, then the category of mines should, according to [1], decrease, and with a decrease in production, it should increase. Such tendencies in the change in the relative gas abundance have led to contradictions in the determination of the mine gas hazard category. They consist in reducing the gas hazard according to [1] with an increase in coal production. This is not consistent with the practice of mining gas-bearing coal seams. It has been unequivocally established that with an increase in coal production, other things being equal conditions, an increase in gas emission is observed [4]. The real gas hazard is increasing, not 
decreasing, as it follows from the definition of the category of mines according to [1].

The above facts testify to the relevance for science and the coal industry of improving the regulatory framework [1,3] in terms of forecasting methane release and establishing the categorization of coal mines by their gas hazard.

The idea of work and purpose. Substantiate the need to change the regulatory framework for forecasting methane release and establish the category hazard of mines by gas factor. Experimentally confirm the theoretical part of the research and give practical suggestions for improving the requirements of regulatory documents for the safe mining of gas-bearing coal seams.

The transition to the development of coal seams at deeper horizons caused changes in the gas balance in terms of its distribution by sources. The share of methane release from the developed seam (broken coal and the exposed surface of the working face) has significantly decreased (up to $10-20 \%$ ). The main sources in the development of seams in deep horizons are undermined and overworked adjacent coal seams and their host rocks (80-90\%). Changes in coal production do not equally affect methane emissions from different, by nature, sources. This led to contradictions in the requirements for the safe mining of gas-bearing coal seams.

Theoretical part. The predominant amount of gas in coal mines is emitted during cleaning works. Based on this ratio of the gas balance between mining operations, on a mine scale, the main gas release is associated with the operation of mining areas. For this reason, we considered the theoretically possible fractions that make up the total relative gas content of the excavation area $q$ in the presence of all possible sources of gas release. Such sources are: the mined seam (broken coal $I_{o y}$ and the exposed surface $I_{о з}$ of the working face), the undermined adjacent seams $I_{c n}$ and their enclosing rocks $I_{n n}$, the overworked adjacent seams $I_{c n}$ and the enclosing rocks $I_{H n}$. The forecast of gas release from the listed sources, without touching on its scientific validity, is made according to [3]. This normative document does not take into account the fact that with a sufficient development of cleaning work in the wing of the mine field, gas release occurs when the movement of the underworked 
coal-rock strata is activated from the worked-out space $I_{6 n}$ of stopped longwalls [5].

For consideration we have accepted gas release from seven possible sources. Methane release from the losses of chipped coal in the worked-out area of the operated and stopped longwalls was neglected. The approximate share of this source with ten percent coal losses does not exceed one percent of the total gas release from the developed seam, and it has no practical effect on the increase in the concentration of methane in the atmosphere of existing mine workings.

The establishment of categorization by the relative gas content of the excavation area $q_{y u}$ according to [1] and on the basis of $n$ sources accepted for consideration can be presented in the following form, $\mathrm{M}^{3} / \mathrm{T}$

$$
q_{y u}=\frac{\sum_{i=1}^{n} I}{A}=\frac{I_{o y}}{A}+\frac{I_{o 3}}{A}+\frac{I_{c n}}{A}+\frac{I_{n n}}{A}+\frac{I_{c h}}{A}+\frac{I_{H n}}{A}+\frac{I_{B n}}{A}+\frac{I_{\partial}}{A},
$$

where $q_{y 4}$ - average monthly relative gas emission per one ton of mined coal, $\mathrm{m}^{3} / \mathrm{t} ; A$ - average monthly coal production, $t$; $I_{o y}, I_{o 3}, I_{c n}, I_{n n}, I_{c H}, I_{n n}, I_{b n} I_{\partial}$ - the average monthly amount of gas released, respectively, from the broken coal, the exposed surface of the working face, adjacent undermined seams, undermined rocks, overworked adjacent seams, overworked rocks, mined-out space of stopped lavas and into degassing systems, $\mathrm{m}^{3}$.

The ratio $I_{o y} / A$ of the right-hand side of equation (1) characterizes the outgassing from one ton of chipped coal. Its numerator $I_{o y}$ is directly related to the amount of coal mined. Broken coal is the most disturbed part of the gas-coal system, from which the rock pressure is completely removed. The parameter $I_{o y}$ has been studied quite fully back in the sixties of the last century. The studies were carried out both in laboratory and in production conditions. All other things being equal, the main factors determining the gas release from the chipped coal are its natural gas content in the mining zone, the fractional composition and the time elapsed since the coal stripping. Gas evolution occurs most intensively in the initial period of time, that is, directly in the face space of the longwall. Usually coal after its breaking is in the bottomhole space for about 10 minutes, and within the site - 30-60 minutes. For this reason, the amount of gas 
released from coal while it is in the bottomhole space is at least $70 \%$ [6]. The share of the evolved gas on the conveyor is several percent [7]. The insignificant release of gas during the transportation of coal from its total amount in the excavation zone is explained by the beginning of intensive gas release from the exposed surface of the seam $I_{0 з}$ a few meters ahead of the executive body of the extraction mechanism [8], a sharp increase in the intensity of gas release in the first minutes of its breaking $[6,9,10]$ and a large residual gas content of coal discharged from the longwall [11].

The processes of gas release from the exposed surface of the seam $I_{о з}$ and chipped coal $I_{\text {oy }}$ are practically impossible to experimentally divide into two components. The relationship between them can be estimated based on the equations of external dynamics of gas release and experimental data on the numerical values of the gas-dynamic parameters of the seam and chipped coal [12]. The calculations performed [7] indicate the predominant gas release from the exposed surface of the working face. This ratio is due to the longer period of methane release from the exposed surface compared to gas release from the chipped coal. This is confirmed by the reduction in the intensity of gas emission from the exposed surface within several months after the termination of coal mining. This period of methane release from the surface of the exposed seam practically does not affect the creation of safe conditions in mine workings in terms of the gas factor. But according to the attitude $I_{03} / A$, the mine in all cases must be attributed to the supercategory. This is explained by the fact that in the absence of coal mining $(A=0)$, insignificant gas evolution occurs for several months $I_{0_{3}}$. In such a situation, the ratio $I_{03} / A$ tends to infinity, which gives a formal basis [1] to transfer the mine to the category of supercategory.

An explosive atmosphere caused by the joint release of gas from the broken coal and the exposed surface of the working face arises in the mining mechanisms during the period of their direct operation lasting, at most, several tens of minutes. This period is incommensurably small in comparison with the monthly average data, according to which the category of mines is established [1]. This indicates that the average monthly parameters $I_{0 y} / A$ and $I_{03} / A$ accepted for consideration do not reflect the real danger of gas release from the developed formation. The danger of exceeding the 
methane concentration standards arises only when the extraction mechanism is operating for several minutes, and its assessment is made according to the average monthly indicators obtained during the past year.

The method for determining the relative gas content according to equation (1) assumes a proportional change in gas release from each source when the load on the working face changes. This assumption was not confirmed by the example of considering the duration of the processes of gas evolution from broken coal and an exposed surface. In addition to the different duration of these processes, they also differ in factors that determine the different mechanism of gas release from the broken coal and the exposed surface of the working face. With some assumptions, we can assume that, other things being equal conditions, and are directly proportional to coal production.

Other sources of gas release $\left(I_{c n}, I_{n n}, I_{c n}, I_{n n}, I_{b n}, I_{\partial}\right)$ do not directly depend on coal mining. The level of gas emission from them, in addition to coal mining, is largely determined by other factors. The tightness of the correlation relationship between gas release from these sources and coal production was established by statistical processing of monthly average experimental data [7]. A distinctive feature of all dependencies is the absence of a direct influence of coal mining on the processes of gas emission from these sources. Depending on the type of violation of the initial natural state of the gas - coal (rock) system, each source has its own distinctive features of the gas release process. Methane release from undermined sources $\left(I_{c n}, I_{n n}, I_{b n}\right)$ depends on the degree of development of treatment works both within the excavation area and in the wing of the mine field. In addition to the displacement of the underworked coal-rock massive, the initial state of methane in them affects the gas evolution from each source. In the coal of adjacent seams, gas is mainly in a sorbed state. In the host rocks, gas can be partially contained in a sorbed state, and a significant amount in a free state, filling the pores. Significant gas release from organic coal substances dispersed in the rocks is not excluded [13].

The overworked gas emission sources $\left(I_{c H}, I_{H n},\right)$ before the treatment are in approximately the same initial natural state as the underworked ones. The difference in the processes of gas evolution 
from them is caused by the conditions of violation of the natural state of the gas - coal (rock) system during overworking.

In the overworked and underworked zones, completely different processes of rock displacement occur, due to different phenomena, which predetermines the distinctive features of gas release from these zones.

The influence of coal mining on methane release in degassing systems $I_{\partial}$ depends, other things being equal conditions, both on the state of the source being degassed and the method used for capturing gas.

Preliminary theoretical analysis shows that the change in coal production does not proportionally affect the change in gas emission from each possible source. This is due to the distinctive features of the natural equilibrium state of gas in coal and rocks, as well as the conditions for violation of this state.

Experimental research. The work was carried out using the known experimental data obtained in the conditions of the mines "Krasnolimanskaya" [2] and them. A.F. Zasyadko [14], as well as the average monthly performance of longwalls for coal mining and methane release in the conditions of the mines named after. newspaper "Izvestia" PJSC "Donbassantratsit", them. D.F. Melnikov of PJSC Lisichanskugol and the Sukhodolskoye - Vostochnoye mine department of PJSC Krasnodonugol, which were previously used to establish the category of these facilities in terms of methane emission hazard.

The absolute and relative gas content of the extraction area of the 3rd southern face of the seam $\ell_{3}$ of the Krasnolimanskaya mine were determined according to [2] using the number of working days. This approach is inconsistent with the outgassing process that continues in the absence of coal mining.

For this reason, using the data [2], we considered the dependences of the absolute $(I)$ and relative $(q)$ gas abundance using the actual periods of longwall operation (Fig. 1).

Several features of these dependencies have been identified. The increase in coal production $(A)$ led to a nonlinear increase in the absolute gas release (Fig. 1a, curves 1,2), and did not change in direct proportion, as indicated by the authors [2]. 
Sharp changes in coal production (Fig. 1b) several times, both upward and downward, did not have a practical effect on the closeness of the relationship between the dependencies $I$ and $q$ with coal production (Fig. 1a).

In all cases, during the period of increasing coal production, there was an increase in the absolute gas release $(I)$ and a decrease in the relative $q$ methane release. With a decrease in $A$, on the contrary, there was a decrease in the absolute gas release $(I)$ and an increase in the relative methane release $q$.

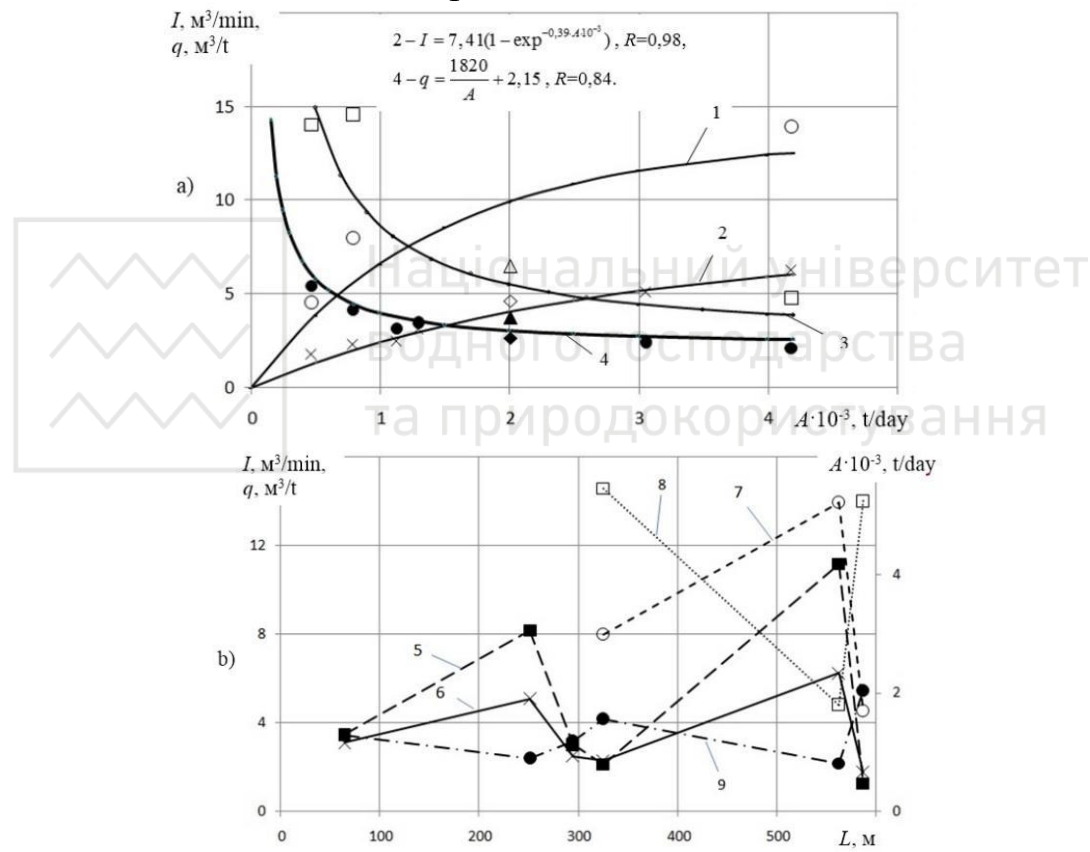

Fig. 1. Dependence of the absolute $(I)$ and relative $(q)$ gas abundance on the production $(A)$ of coal $(a)$ and movement $(L)$ of the working face (b) during the development of the seam $\ell_{3}$ by the Krasnolimanskaya mine according to [2]:

1 - averaging curve of the absolute total gas release into mine workings and degassing wells; 2 - averaging curve of absolute gas release into mine workings; 3,4 - curves of relative gas release, respectively, total and into mine workings; 5-8; 9 change, respectively, of coal production (5), absolute gas release in workings (6) and total (7) in workings and wells, relative total gas release (8) and relative gas release in workings (9); - - experimental data of changes in coal production $(A)$ as the working face moves $(L) ; \circ, \times-$ experimental data of absolute gas release, 
respectively, total and into mine workings in certain periods of longwall operation; $\square, \bullet-$ experimental data on the relative gas release, respectively, of the total and into mine workings in certain periods of exploitation of the extraction area; $\Delta, \boldsymbol{\Lambda}, \diamond,-$ experimental data on the results of operation of the site for the entire observation period, respectively, the average absolute total gas release, average absolute gas release in mine workings, average relative total gas release and average relative gas release in mine workings

For the first three months, the mining area was operated without degassing any sources of methane release. In the next three months, degassing of undermined adjacent layers $\ell_{4}, \ell^{\prime}{ }_{4}$ and worked-out space by wells was used [2]. Capturing with the help of wells more than half of the amount of gas from its total release did not affect the nature of the change in the dependence of the absolute gas release in workings (2) on coal production (Fig. 1a). This fact indicates the absence of aerodynamic connection between the degassed sources and mine workings during the period of the cleaning work.

This situation is explained by the considerable duration of the processes of displacement of underworked rocks and the time lag behind them of gas release into mine workings [15]. Along with this, there are sources of methane release in the mining areas, which are not directly related to the processes of displacement of the undermined rocks. These include chipped coal, the exposed surfaces of the seam being mined, and the enclosing roof and soil rocks immediately adjacent to the seam. Gas release from these sources mainly depends on the intensity of development of the developed formation. In this case, the dependence of gas release in mine workings on coal production is not affected by changes in the degassing conditions by wells of remote, at some distance, adjacent layers. This is confirmed [7] by the operation of excavation areas in the conditions of the mine named after. newspapers "Izvestia" on a layer $\ell_{2}^{b}$ in the undeveloped and overworked zones, $70 \mathrm{~m}$ distant by the adjacent layer $\ell_{4}$. The overworking did not affect the decrease in gas emission in the workings of the working areas, which was confirmed by the same dependence of methane release on the load in the overworked and undeveloped zones.

In the conditions of the Krasnolimanskaya mine, the introduction of degassing of undermined sources by wells also did not affect the 
change in the dependence of gas release in production (Fig. 1a, curve 2) on the average daily coal production. The above facts indicate that gas release into mine workings from some sources is characterized by a stable dependence on coal mining. This is also confirmed by the fact that the average absolute and relative gas release for the entire observation period, with an average daily coal production of $2010 \mathrm{t}$, coincide with the dependencies $(2,4)$ during the operation of the mining area in certain periods of time (Fig. 1a). In this case, the average indicators $I$ and $q$ did not depend on the duration of the considered periods of exploitation of the mining area, but were determined only by the average values of coal production during these periods.

Using similar dependencies typical for some mining-geological and mining-technical conditions, it is possible to reliably predict gas release into mine workings at any load on the working face. The proof of the legitimacy of this approach are the results obtained during the operation of the extraction areas by the SukhodolskayaVostochnaya mine during the development of the seam $i_{3}^{\prime}$. The seam was mined by long pillars along strike at a depth of more than 1000 $\mathrm{m}$. In all areas, contiguous formations were degassed by wells drilled from underground workings. In most cases, in addition to them, wells were drilled from the earth's surface.

The mining-geological and mining-technical conditions for the development of mining areas, from the standpoint of the same dependence of gas release in mine workings on the average daily coal production, despite the differences in the methods and efficiency of degassing the undermined sources, were identical (Fig. 2). This dependence was characterized by a high correlation ratio $(R=0.86)$ for the five mined mining areas. The change in the average daily coal production was in the range of 75-2333 tons. The root-mean-square deviation of gas release in the workings from the averaging curve was $2.2 \mathrm{~m}^{3} / \mathrm{min}$ or $16.9 \%$. This makes it possible to classify the considered lavas as analogous lavas according to the criterion of gas release into mine workings. When the average daily coal production reached 1.0-1.3 thousand tons, the average gas emission in the mine workings stabilized at about $18.0 \mathrm{~m}^{3} / \mathrm{min}$. Its actual fluctuations were in the range of $15.7-20.1 \mathrm{~m}^{3} / \mathrm{min}$. This indicates the stabilization of 
gas emission in production at a certain level, which does not depend on a further increase in coal production [15].

In contrast to gas release into workings with an average daily coal production of more than 2 thousand tons, the maximum total gas release into workings and degassing systems was not reached (Fig. 2). This follows from a comparison of the experimental data of the maximum gas release $\left(62.4 \mathrm{~m}^{3} / \mathrm{min}\right)$ and the empirical coefficient (90.61) of the exponential equation (Fig. 2). The value of this coefficient of 90.61 indicates the possibility of reaching a maximum total gas release with the average daily coal production significantly exceeding 2.3 thousand tons. According to approximate calculations, the maximum total gas release in mine workings and degassing systems can be achieved with an average daily coal production of about 20 thousand tons. This indicates significant gas resources in the undermined coal strata. Large deviations of the experimental data $\left(\sigma=4.3 \mathrm{~m}^{3} / \mathrm{min}\right)$ from the averaging curve indicate a significant influence of factors other than coal mining. These include, first of all, the intensity of the processes of displacement of the undermined rocks.

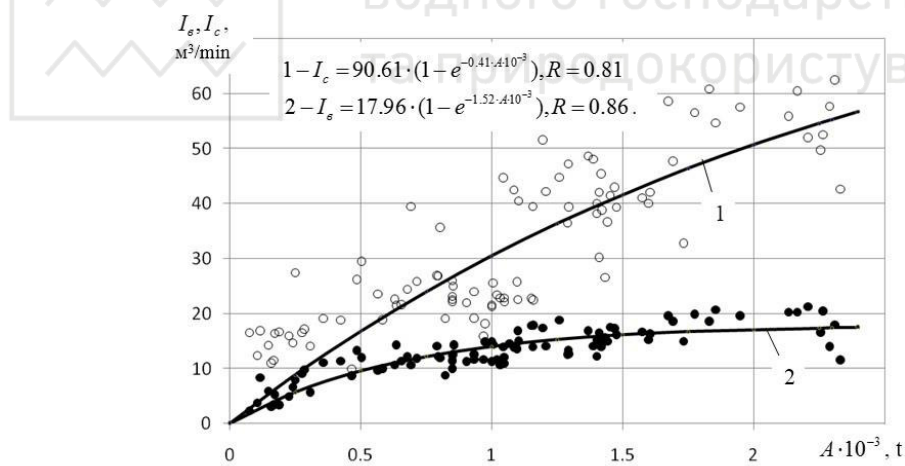

Fig. 2. Dependence of methane release $(I)$ on the average daily coal production (A) during the operation of the excavated sections of the SukhodolskayaVostochnaya mine (12th eastern unloading, 12th bis eastern, 24th eastern, 24th western and 25th I'm western lava): 1,2 - averaging curves, respectively, of the total $\left(I_{c}\right)$ and methane release into mine workings $\left(I_{b}\right) ; \bullet, \circ-$ experimental data, respectively, of total and methane release into mine workings; $R$ is the correlation ratio

Stabilization of the level of maximum gas release in mine workings and an increase in its total methane release at the achieved loads on the production faces, indicates the capture of a significant 
part of methane by degassing systems, which is not released into the mine workings.

Statistical processing of experimental data [14] obtained in the conditions of the mine. A.F. Zasyadko, indicates a significant resource of gas in the undermined coal-bearing strata. During the operation of the 16th eastern lava of the seam $m_{3}$, the undermined sources were degassed by wells drilled from underground workings and from the earth's surface. In addition, the gas mixture was removed from the worked-out space. With an average daily coal production of about 3 thousand tons, the maximum absolute gas release reached $108.5 \mathrm{~m}^{3} / \mathrm{min}$. The dependence of the total amount of released gas $\left(I_{c}\right)$ from all sources was directly proportional to the average daily coal production $(A), \mathrm{M}^{3} / \mathrm{min}$

$$
I_{c}=0.029 \cdot A+6.6 \text {. }
$$

The dependence of the relative gas content was described by an isosceles hyperbola with asymptotes $A=0 \mathrm{t}$ and $=42.2, \mathrm{M}^{3} / \mathrm{t}$

$$
q=\frac{9484}{A}+42.2 \text {. }
$$

The tightness of the relationship between the total absolute gas release and coal production was characterized by a high correlation coefficient $(r=0.84)$. The relative gas abundance was less dependent on coal production (correlation ratio $R=0.39$ ).

To establish a more detailed change in the absolute and relative gas release, we considered the change in three parameters $A, I$ and $q$ with the distance $L$ of the working face from the cut (Fig. 3).

The first maximum of absolute gas release was reached two months after the start of exploitation of the extraction area. When the working face moved away from the split furnace at a distance of about $200 \mathrm{~m}$, the main roof apparently settled.

During this period $I$ of longwall operation, coal production $A$, absolute $I$ and relative $q$ gas release increased in parallel. An increase in the relative gas content $q$, along with an increase in $\mathrm{A}$, is explained by the development of the processes of displacement of the undermined coal-rock strata and an increase in absolute gas release from it. 
At the next stage of exploitation of the mining area (II), the maximum coal production was reached.

For unknown reasons, during this period, with an increase in coal production from 2514 to 2824 tons/day, the total absolute gas emission decreased from 91.0 to $70.0 \mathrm{~m}^{3} / \mathrm{min}$. As a result, the relative gas emission also decreased from 52.1 to $35.7 \mathrm{~m}^{3} / \mathrm{t}$.

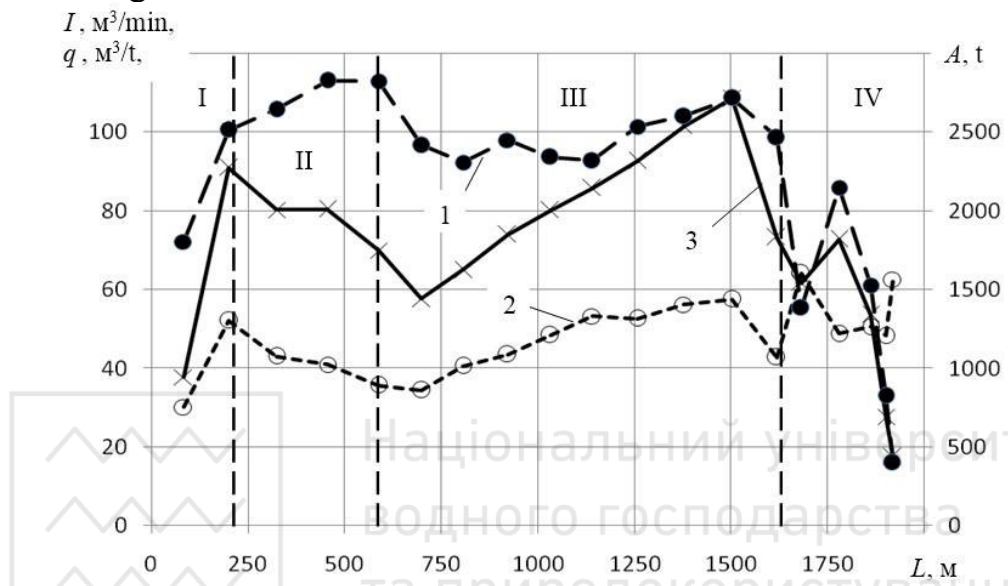

Fig. 3. Change in coal production $(A)$, absolute $(I)$ and relative $(q)$ gas abundance at the distance $(L)$ of the working face from the split furnace of the 16th eastern longwall of the seam $m_{3}$ of the mine named after I. A.F. Zasyadko according to [14]: 1,2,3 - curves of change, respectively, of coal production, relative and absolute gas release; $\times, \bullet, \circ$ - experimental data; I, II, III, IV - typical periods of exploitation of the mining area

The third stage of exploitation of the mining area (Fig. 3) was distinguished by stable coal production (2320-2716 tons/day). Fluctuations in absolute gas emission occurred during this period synchronously with changes in coal production. As a result, the relative gas evolution changed in a similar way.

The fourth stage is associated with a reduction in coal production before stopping the longwall. During this period, for several months, coal production decreased to 402 tons/day. The absolute gas emission decreased to $17.5 \mathrm{~m}^{3} / \mathrm{min}$, and the relative one increased to $62.6 \mathrm{~m}^{3} / \mathrm{t}$.

Based on the results of the analysis of experimental data obtained in the conditions of the mine. A.F. Zasyadko [14], it follows that, 
along with coal mining, the absolute and relative gas release is influenced by the development of cleaning operations and the associated processes of displacement of underworked rocks.

The influence of these factors was confirmed by experimental data obtained during the development of the seam $\ell_{6}$ with the 1 st northern longwall of the mine named after D.F. Melnikov. Observations were carried out for five years from 2014 to 2018 inclusive. A characteristic feature of the operation of the mining area was, with a relatively low productivity, significant fluctuations in coal production. The maximum coal production in rare cases exceeded 1000 tons/day.

Along with this, there were periods when coal mining was absent for several months. Methane emission sources were not degassed. Absolute $(I)$ and relative $(q)$ gas release into mine workings, depending on coal production $(A)$, were described by nonlinear equations (Fig. 4a).

With the growth of coal production, the absolute gas release increased exponentially (curve 1). On the contrary, the relative gas content decreased according to the hyperbolic dependence (curve 2).

Significant deviations of the absolute gas release from the averaging curve (1) were observed to the smaller side when the working face moved away from the split furnace at a distance of up to $100 \mathrm{~m}$.

This was caused by the insufficient development of the processes of displacement of the undermined coal-rock strata to the settlement of the main roof and, as a result, not all sources of methane release fell into the zone unloaded from rock pressure.

Deviations of the absolute gas release values from the averaging curve (1) towards excess were observed with a sharp decrease in coal production or its absence. This is due to the fact that even in the absence of coal mining, gas is released from some sources for several months (Fig. 4a).

Insignificant fluctuations in the relative gas release were observed (curve 5) during the active cleaning work (Fig. 4b). 
Its abnormal bursts occurred at the level of coal production, close to zero or its absence.

This nature of the change in the relative gas abundance predetermined its dependence on coal production according to the hyperbolic dependence (curve 2, Fig. 4a).

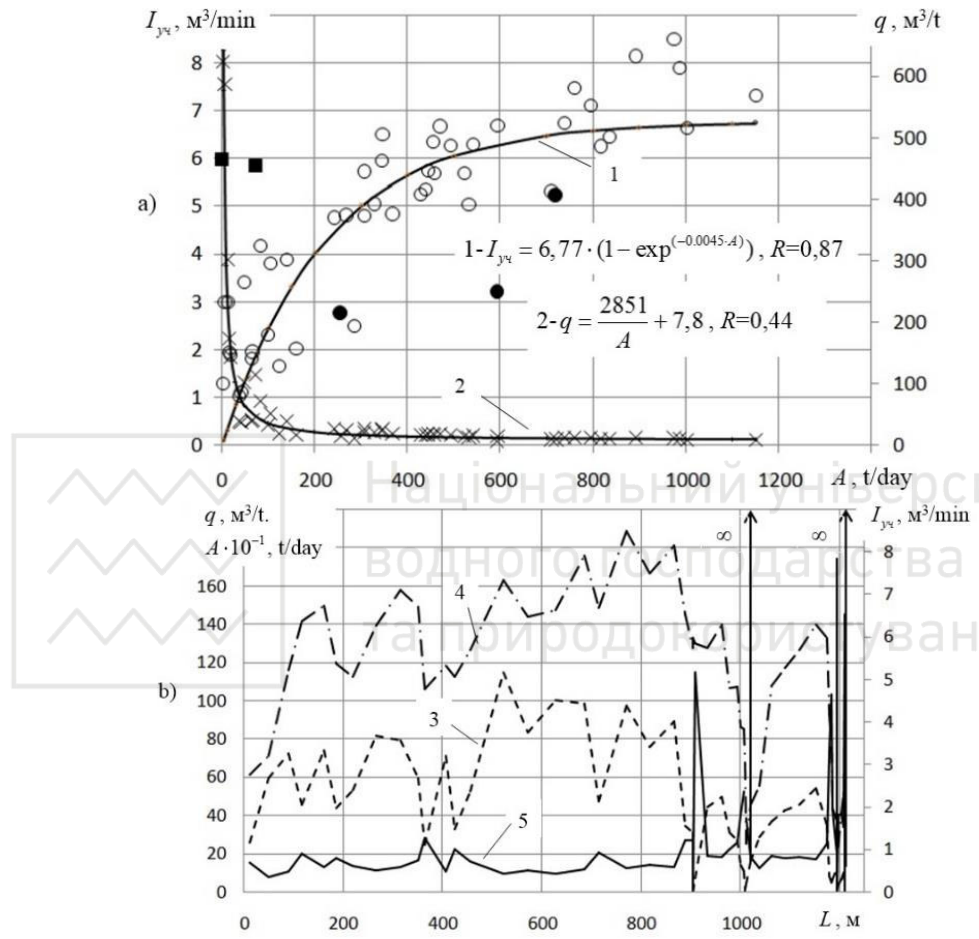

Fig. 4. Dependence of the absolute $(I)$ and relative $(q)$ gas abundance on the production $(A)$ of coal (a) and the movement $(L)$ of the working face $(b)$ of the 1st northern lava of the seam $\ell_{6}$ of the mine named after D.F. Melnikov: 1, 2 averaging curves of changes in absolute and relative gas release, respectively; $3,4,5$ - change, respectively, of coal production (3), absolute (4) and relative (5) gas release; $\times, \circ$ - experimental data; •, - - experimental data, respectively, in the initial period of longwall operation or a sharp decline in coal production; $\infty \mathbb{\Lambda}$ - value of $q$ at $A=0 ; R$ is the correlation ratio

Similar studies of changes in the absolute and relative gas release during the development of the extraction pillar were carried out during the operation of the 9 th western face of the seam $\ell_{2}^{b}$ by the 
mine named after newspaper "Izvestia". Its characteristic features were:

- the lack of cleaning works in the wing of the mine field for two months before the commissioning of the 9th western longwall;

- a smooth increase in coal production both when the stope is removed from the split furnace, and its decrease before the stopping of the longwall;

- significant development of cleaning works in the wing of the mine field. Before the start of anthracite mining in the 9th western longwall, ten longwalls were mined in the wing of the mine field;

- at the site, the undermined sources were degassed by wells. Outside the mining area, there were wells connected to the degassing system after the shutdown of previously worked longwalls.

These features of the operating conditions of the 9th western longwall made it possible to establish the patterns of gas evolution both within the mining area and beyond its boundaries with the activation of the movement of underworked rocks.

The absolute total gas release in the wing of the mine field $I_{\kappa p}$ depended directly on coal production (Fig. 5a, line 1). Within the mining area, the absolute gas release $I_{y u}$ changed exponentially (curve 2). Below this averaging curve, with significant deviations, are the experimental values of the absolute gas release, obtained before the settlement of the main roof. Previously, for the conditions of the mine. According to the Izvestia newspaper, according to the level of gas emission into the wells, it was established [5] that the sediment of the main roof occurs when the working faces are removed from the cut workings at a distance of 80-120 m.

The development of the processes of displacement of the coalrock strata to the settlement of the main roof caused a more intense absolute gas release in the wing of the mine field compared to an increase in the absolute gas release within the mining area. Such a difference in the intensity of absolute gas release between $I_{k p}$ and $I_{y u}$ is established on the basis of the location of the corresponding averaging $(1,2)$ on the graph (Fig. $5 a$ ). The relative gas content of the mine field wing from coal production changed according to the hyperbolic relationship (curve 3). According to a similar relationship, 
there was a change in the relative gas content $q_{y 4}$ of the excavation area (not shown in the figure), $\mathrm{m}^{3} / \mathrm{t}$

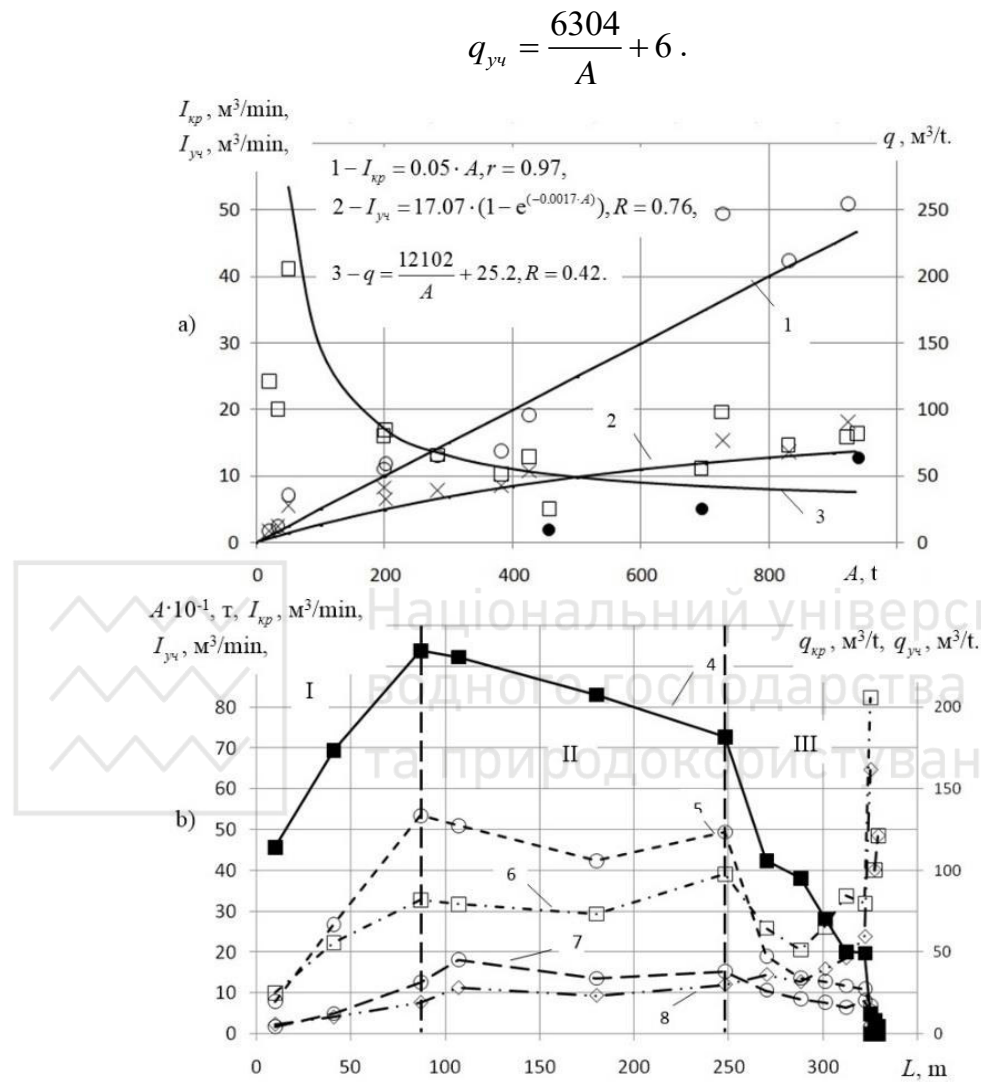

Fig. 5. Dependences of the absolute $(I)$ and relative gas abundance $(q)$ on the production (A) of coal (a) and the distance $(L)$ between the stope and the split furnace (b) during the development of the 9th western face of the seam $\ell_{2}^{b}$ by the mine named after newspaper "Izvestia": 1 - averaging straight line of the absolute gas release in the wing of the mine field $\left(I_{k p}\right) ; 2$ - averaging curve of absolute gas release within the mining area; 3 - averaging curve of the relative gas release in the wing of the mine field; 4, 5, 6, 7, 8 - change, respectively, of coal production (4), absolute (5) and relative (6) gas release in the wing of the mine field and within the excavation area $(7,8) ;$ - - change in coal production as removal of the stope from the split furnace; $\times, \circ$ experimental data of the absolute total gas release in the wing of the mine field and within the excavation area; $\square, \diamond$ - experimental data on the change in the relative gas release, respectively, in the wing of the mine field and 
within the excavation area; - - experimental data of absolute gas release before settlement of the main roof; $r, R$ - correlation coefficient and correlation ratio, respectively; I, II, III - stages of exploitation of the mining area, respectively, when the planned coal production indicators are achieved, stable operation and a reduction in coal production before stopping the working face

The tightness of the correlation between $q_{y^{4}}$ and $\mathrm{A}$ was characterized by a correlation ratio $R$ equal to 0.75 .

The features of the change in the considered parameters $A, I_{k p}, I_{y u}$ and $q_{k p}$ as the distance $(L)$ of the working face from the split furnace is shown in the graph (Fig. 5b). According to it, three characteristic stages of exploitation of the mining area can be distinguished, due to the peculiarities of changes in coal production and gas emission. The growth of coal production (A), absolute $I_{k p}, I_{y u}$ and relative gas release $q_{k p}, q_{y u}$ before the main roof settling occurred synchronously between these parameters (stage I).

The second stage was characterized by relatively stable coal production. The absolute $I_{k p}, I_{y 4}$ and relative gas evolution $q_{k p}, q_{y u}$ were subject to insignificant fluctuations during this period.

The third stage is associated with a steady decline in coal production before stopping the longwall. This led to a decrease in the absolute gas release in the wing of the mine field and within the excavation area to $1.6 \mathrm{~m}^{3} / \mathrm{min}$. With a decrease in coal production, a specific maximum relative methane content of the excavation area and the wing of the mine field was recorded, the value of which was determined by the real figure of $205.7 \mathrm{~m}^{3} / \mathrm{t}$. After stopping the working face and stopping production $(A=0)$, the values $q_{\kappa p}$ and $q_{y 4}$ tended to infinity.

Such an increase in the relative gas abundance and a decrease in the absolute gas release leads to contradictions in the definition of the category hazard of coal mines according to [1]. In particular, they consist in reducing the real gas hazard with a decrease in the absolute gas release, and the determination of the categorization by the relative gas abundance with insignificant coal production allegedly indicates an increase in this hazard.

Scientific and practical conclusions. Long-term (from 6 months to 8 years) observations under the conditions of five mines made it possible to analyze and generalize the experimental data of absolute and relative gas release depending on the influencing factors. The 
main factor that determines both absolute and relative gas release is coal production and its fluctuations throughout the entire period of operation of the mining area. Formally, in all cases, an increase in coal production led to an increase in trends in absolute $(1,2,3)$ and a decrease in relative (4) gas release (Fig. 6a).

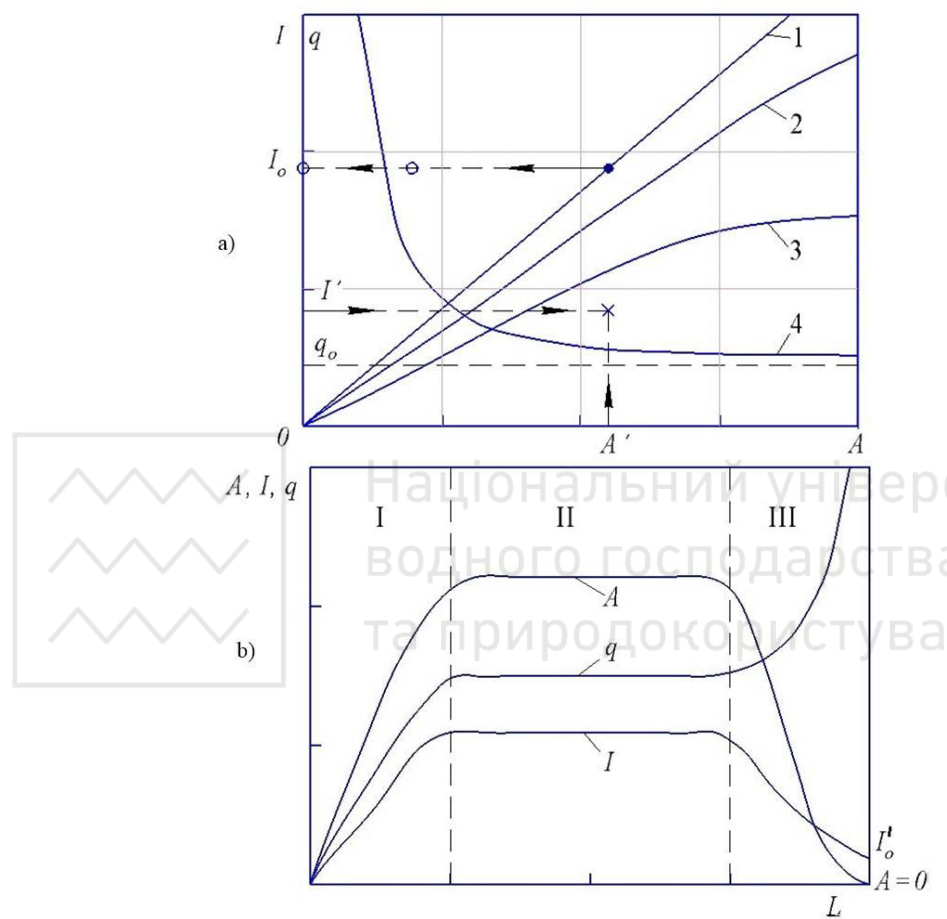

Fig. 6. The results of the analysis of the experimental data of the dependence of the absolute $(I)$ and relative gas content $(q)$ of mining areas on the production $(A)$ of coal $(a)$ and the change in these factors with the distance $(L)$ of the stope from the split furnace $(b): 1,2,3$ - possible types of dependence of absolute gas release on coal production; 4 - change in the relative gas emission from coal mining; I, II, III stages of exploitation of mining areas, respectively, in the initial period before the settlement of the main roof, stable operation and a decrease in coal production before stopping the longwall; $\times$ - experimental data $\left(A^{\prime}, I^{\prime}\right)$ observed before settlement of the main roof at the first stage of exploitation of the mining area; $\bigcirc-$ experimental values of absolute gas release $\left(I_{o}\right)$ with a sharp reduction in coal production or its temporary cessation; $I_{o}^{\prime}$ - the level of absolute gas release at the moment of stopping the longwall $(A=0) ; q_{0}$ - the asymptote of the hyperbole of the dependence of the relative gas release on coal production 
The absolute gas evolution varied according to different dependences for each observed object. In some cases, at the achieved level of coal production, it changed according to a direct proportional relationship (straight line 1, Fig. 6a). Such a dependence of the total absolute gas release in mine workings and degassing systems was observed in the conditions of the mines named after A.F. Zasyadko and them newspaper "Izvestia" in the development of seams with high natural gas content of coal (up to $35 \mathrm{~m}^{3} /$ t.d.a.m.). The total absolute gas release into mine workings and degassing wells, including those drilled from the surface, during the development of the seam $i_{3}^{\prime}$ by the Sukhodolskaya - Vostochnaya mine (curve 2, Fig. 6a) was found close to a direct proportional relationship. The natural gas content of the coal in the developed seam was $33 \mathrm{~m}^{3} /$ t.d.a.m.

At a lower natural gas content $\left(6-8 \mathrm{~m}^{3} / \mathrm{t}\right)$ in the conditions of the mines "Krasnolimanskaya" and them D.F. Melnikov, the absolute gas release at the achieved level of coal production tended to a certain limiting value. In these cases, the change in the absolute gas release occurred according to a clearly pronounced exponential dependence (curve 3, Fig. 6a).

According to a similar relationship, gas was released into the local mine workings of the mines named after. newspaper "Izvestia", them. D.F. Melnikov, Krasnolimanskaya and SukhodolskayaVostochnaya. This confirms the stated assumption about the stabilization of the absolute gas release in the area workings at a certain level, which does not depend on a further increase in coal production.

The analysis made it possible to establish some features of the dependence of the absolute gas release on the level of coal production. In all cases, in the initial period of exploitation of the mining areas before the main roof settling, along with the increase in coal production, the absolute gas emission also increases. But all experimental points during this period are significantly below the averaging lines (Fig. 6a). This situation is due to the insufficient development of the processes of displacement of underworked rocks.

With a sharp decrease in coal production or its temporary cessation, the experimental points of absolute gas release are located 
significantly above the averaging lines. This indicates the presence of gas emission immediately after stopping the treatment.

In all considered cases, the relative gas release $q$, depending on the level of coal production, changed according to the hyperbolic dependence (curve 4, Fig. $6 a$ ). One asymptote of this hyperbola $A=0$, and the second is equal to the free term $q_{o}$ of this equation.

The considered parameters $A, I, q$ and change ambiguously with the distance $L$ of the working face from the split furnace (Fig. $6 b$ ).

Working out of cut areas with long faces, as a rule, is characterized by three stages. This is due to the technological and organizational features of the treatment. After putting the excavation site into operation, the equipment is tested and the identified deficiencies and malfunctions are eliminated. For this reason, it is practically impossible from the first days of exploitation of the mining area to ensure the planned indicators of coal production. At the stage of increasing coal production $(A)$, there is an increase in both absolute gas release $(I)$ and relative $(q)$ (Fig. $6 b$ ).

After reaching the planned indicators and the settlement of the main roof, coal production is stabilized (stage II) and its fluctuations are insignificant. As a result of this insignificant irregularities are subject to absolute and relative gas content.

At stage III, before stopping the working face, a decrease in coal production is observed, and, as a consequence, a decrease in absolute gas emission. The rate of decline in coal production outstrips the decline in absolute gas emission. For this reason, taking into account the equality $q=I / A$, there is an increase in the relative gas release, and when the cleaning work is stopped $(A=0)$, the relative gas release tends to infinity (Fig. 6b).

At all three stages of the cleaning work, some fluctuations in the parameters $A, I, q$ are possible, and in the direction of their increase or decrease, but they do not change the trend of the averaging curves (Fig. 6b).

At all stages of exploitation of mining areas, the averaging absolute gas release corresponds to the direction of change in coal production. The direction of the change in the relative gas release at all three stages of the treatment works occurs in different ways. At the first stage, it increases synchronously with coal production, at the second, it stabilizes at a certain level, at the third, it increases with 
the reduction and termination of coal mining (Fig. 6b). The ambiguous direction of the change $q$ at the stages of cleaning works predetermines its lower correlation dependence on coal production in comparison with the analogous dependence of the absolute gas release.

The tightness of the relationship between the relative gas release and coal production was characterized by the values of the correlation ratio $(R)$, which are in the range of $0.39-0.84$. The dependence of the absolute gas release was characterized by higher correlation indicators (0.81-0.97).

This testifies to the instability of the relative gas release throughout the development of mining areas, as an indicator of the category hazard of mines in terms of the gas factor. Its use does not guarantee an adequate establishment of the mine's categorization, and with it the level of hazard in terms of the gas factor.

The use of relative gas abundance as a criterion for assessing gas hazard leads to contradictions between the requirements of the regulatory document [1] and the results of the experience of mining gas-bearing coal seams.

The maximum danger in terms of the gas factor arises at the second stage of the cleaning work. During this period, stable coal production takes place and the maximums of absolute gas emission are reached. At the same time, the relative gas abundance tends to its minimum value, which supposedly indicates a minimum gas hazard.

At the final stage (III) of the cleanup, there is a decrease in coal production and a stop of the longwall. The absolute gas emission is reduced to a minimum, and consequently the hazard in terms of the gas factor is reduced. The relative gas release increases, and after the termination of cleaning work tends to infinity. This indicates an apparent increase in the gas hazard in accordance with the regulatory document [1].

The above examples indicate that the relative gas release is not a sufficiently informative indicator. According to its level, all mines in Ukraine are divided [1] into four categories ranging from zero to 15 $\mathrm{m}^{3} / \mathrm{t}$ and more. Based on the experience of the mines, this indicator varies in a much wider range from zero to infinity, which gives grounds for almost all gas mines to be transferred to the category of supercategory. The categorization of mines in this case is not a reliable criterion for their distribution by gas hazard. 
The most acceptable indicator of gas hazard is absolute methane release, since it determines the possibility of hazardous gas mixtures formation and the choice of measures to ensure safe conditions in mine workings.

The direction of the change in the trend of absolute gas release unambiguously repeats the fluctuations in coal production at all stages of exploitation of mining areas. For this reason, close correlations have been established between the parameters $A$ and $I$. Substantial deviations of the experimental data on absolute gas release from the averaging functions of the dependence $I=f(A)$, other things being equal, are possible only in two cases. In the first, the experimental data were obtained in the initial period of exploitation of the excavation area before the settlement of the main roof. The experimental points of absolute gas release at this stage are located below the averaging curves. In the second, the experimental points of absolute gas release are above these curves, which is caused by a temporary sharp decrease or cessation of coal production. Other anomalous deviations of the absolute gas release from the averaging lines can occur only when the mining-geological and miningtechnical conditions change. These include a change in the natural gas content of possible sources, underworking or overworking of the developed layer close to each other, the entry of the production face into the zones of influence of geological disturbances or increased rock pressure, etc. Proposed changes in mining and geological and mining technical conditions are established by the relevant services of coal mining enterprises. Changes in treatment conditions can be taken into account at the stage of preparation of technical documentation. This makes it possible to timely adjust the forecast of absolute gas release.

The tendency to change the coal production and absolute gas release occurs as the distance $(L)$ of the working face from the split furnace to the complete mining of the extraction column.

Coal mining clearly characterizes the absolute gas release only from the chipped coal and the exposed surface of the working face. According to its values, it is not possible to analyze the absolute gas release from other sources when mining technical or mining and geological factors change. 
With the prevailing methane release from the undermined coalrock strata, the absolute gas release, all other things being equal, depends on the intensity of the displacement of the enclosing rocks. The main factor that determines the intensity of rock displacement processes is the rate of movement of the working face $v_{\text {оч. }}$. The geometrical dimensions of the worked-out area functionally correspond to the monthly average values $v_{o u}$, in addition to coal mining. They give more visual information about the undermined area of the coal-rock strata in each specific case.

With all possible options for the combination of mining and geological factors, the rate of movement of the working face $(c)$ determines the level of coal production $(A)$. The presence of such a dependence makes it possible to consider the geometrical dimensions of the mined-out space

$$
A=k \cdot v_{o u}=L_{n} \cdot m \cdot \gamma \cdot v_{o u},
$$

where $k$ - the coefficient of proportionality; $L_{\pi}$ - the length of the lava; $m$ - the recoverable thickness of the developed formation; $\gamma$ the specific gravity of coal.

The combination of the parameters $L_{l}, m, \gamma$ make it possible for each object under consideration by means of the coefficient $(k)$ to establish a relationship between $v_{о 4}$ and A. The product $L_{\pi} v_{\circ 4}$ characterizes the area $(S)$ of the underworked coal-rock strata for a month. It corresponds to the absolute gas emission that is emitted from the undermined sources. With a constant face length $\left(L_{\pi}\right)$, the parameters $A, v_{o u}, S$ are functionally mutually correlated with each other. This gives grounds to use any of them to analyze the change in the absolute gas release from the undermined coal strata.

By removing the stope from the split furnace $(L)$ and the area of the mined-out space of the exploited section and the wing of the mine field, taking into account the stopped longwalls, it is possible to predict the processes of rock displacement, which determine the absolute gas release from the undermined sources.

The performed theoretical studies and analysis of experimental data show that when determining the relative gas content of mine workings for each excavation site operated in specific mining and geological and mining conditions, according to [1], it is necessary to 
preliminarily establish the absolute gas emission corresponding to a certain level of coal production.

Taking into account the results of the studies carried out and the complex interdependence of the considered parameters with an ambiguous change in the relative gas release, there is no need for its preliminary determination according to the established values of the absolute gas abundance. This indicates the advisability of developing a fundamentally new method for assessing the hazard of coal mines, based on the direct determination of the absolute gas release from the sources of its entry into mine workings and degassing systems.

\section{References}

1. Pravila bezpeki u vugil'nih shahtah (NPAOP 10.01-1.01-10, Kiev, 2010).

2. I.F. Yarembash, V.I. Beskrovnyj, S.P. Fishchenko, A.E. Bludov, Ugol' Ukrainy. 1, 37-39 (1969).

3. Rukovodstvo po proektirovaniyu ventilyacii ugol'nyh shaht / Yanko S.V. i dr. K.: Osnova, 1994. 311p.

4. M.V. Filatiev, N.I. Antoshchenko, A.I. Dubovik, Geomekhanicheskie processy sdvizheniya podrabotannyh porod i obosnovanie metodiki prognoza gazovydeleniya v ugol'nyh shahtah (Lisichansk, DonSTU, 2017).

5. N.I. Antoshchenko et al., Bezopasnaya otrabotka gazonosnyh ugol'nyh plastov s uchetom geomekhanicheskih processov sdvizheniya podrabotannyh porod (Alchevsk, DonSTU, 2014).

6. Zhupahina, E., \& Ustinov, N. (Trans.). (1967). Gazovydelenie iz otbitogo uglya. Rudnichnaya Aerologiya I Bezopasnost' Truda v Shahtah. Nauchnye Soobshcheniya. IGD Im. A.A. Skochinskogo, 26-36.

7. Antoshchenko N.I. et al., Geomekhanicheskie processy i prognoz dinamiki gazovydeleniya pri vedenii ochistnyh rabot v ugol'nyh shahtah (Alchevsk, DonSTU, 2010)

8. A.S. Cyrul'nikov, I.Y. Eryomin, V.F. Mikitchenko, V.P. Ponomaryov, Ugol' Ukrainy. 11, 46-48 (1969)

9. Kuz'min D.V., Mibchuani A.G., Nedviga S.N. (1968) Prognozirovanie metanovydeleniya iz razrabatyvaemogo plasta pri vysokoj proizvoditel'nosti zaboev. Sovershenstvovanie ventilyacii i sposobov bor'by s pyl'yu i gazom v ugol'nyh shahtah. IGD im. A.A. Skochinskogo. 171.14-18.

10. Petrosyan A.E., Sergeev I.V., Ustinov N.I. (1968) Gazovydelenie pri rabote uzkozahvatnyh kombajnov. Rudnichnaya aerologiya i bezopasnost' truda $\mathrm{v}$ shahtah. IGD im. A.A. Skochinskogo.M.: Nedra. 15-23.

11. Fertel'mejster, Y. N. (Trans.). (1962). Issledovanie gazoyomkosti uglej i gazonosnosti plastov. Metody Opredeleniya Gazonosnosti Plastov I Prognoz Gazoobil'nosti Shaht: Trudy Vsesoyuznogo Nauchno-tekhnicheskogo Soveshchaniya, 25-35.

12. Klebanov, F., \& Firchanek, B. (1981). Prirodnye opasnosti v shahtah, sposoby ih kontrolya i predotvrashcheniya (E. Karpov, Trans.). M: Nedra. 
13. V.V. Lukinov, A.P. Klec, B.V. Bokij, I.A. Efremov, Ugol' Ukrainy. 1, 50$53(2011)$

14. V.V. Bokij, O.I. Kasimov, Ugol' Ukrainy. 5, 17-21 (2005).

15. Kryzhanovskij, Y., \& Antoshchenko, N. (2014). O maksimal'nom gazovydelenii $\mathrm{v}$ gornye vyrabotki pri otrabotke ugol'nyh plastov (R. Gasyuk, Ed.). Sb. Nauchnyh Trudov MakNII, 2(32), 69-76.

https://doi.org/10.31713/m1016

MODELING OF PHOSPHORUS PRODUCTION PROCESSES AND DEVELOPING A MANAGEMENT STRUCTURE BASED ON GREY SYSTEMS

\section{Toktasynova Nigina}

Satbayev University, Master of Engineering and Technology, Junior Researcher of Department "Automation and Control”, Kazakhstan

\section{Suleimenov B. A.}

Satbayev University, Doctor of Engineering Sciences, Professor of

Department "Automation and Control", Kazakhstan.

Hassen Fourati, PhD, Associate Professor of Gipsa Lab, Grenoble, France

\section{Kulakova Ye.A.}

Satbayev University, Master of Engineering and Technology, Lecturer of Department "Automation and Control", Kazakhstan

\section{Abstract}

The agglomeration process is one of the complex, multidimensional technological processes; it takes place under conditions of a large number of disturbing influences. As a result, the amount of return during sintering reaches $40-$ $50 \%$.

The work is devoted to the development of a mathematical model capable of predicting and controlling the sintering point based on real-time data. As the main parameters for the construction of predictive models, data measured in real time were used - the temperature in the vacuum chambers and the gas velocity determined through the measured pressure (rarefaction) in the vacuum chambers.

This paper describes the methodology and basic algorithms for modeling agglomeration processes, starting from the ingress of the charge into the sinter machine and ending with the production of a suitable agglomerate. The obtained curves of the developed mathematical model of temperature in vacuum chambers served as the basis for testing the forecast model based on the use of the theory of gray systems and the optimization algorithm of the "swarm of particles". Based on the developed mathematical model, a system for predicting the sintering point is constructed, which is the basis for determining the quality of the agglomerate, which 